\title{
ON THE MAXIMAL OPERATORS OF VILENKIN-FEJÉR MEANS ON HARDY SPACES
}

\section{GEORGE TEPHNADZE}

Abstract. The main aim of this paper is to prove that when $0<p<1 / 2$ the maximal operator $\tilde{\sigma}_{p}^{*} f:=\sup _{n \in \mathbb{N}} \frac{\left|\sigma_{n} f\right|}{(n+1)^{1 / p-2}}$ is bounded from the martingale Hardy space $H_{p}$ to the space $L_{p}$, where $\sigma_{n}$ is $n$-th Fejér mean with respect to bounded Vilenkin system.

Mathematics subject classification (2010): 42C10.

Keywords and phrases: Vilenkin system, Fejér means, martingale Hardy space.

\section{REFERENCES}

[1] G. N. Agaev, N. Ya. Vilenkin, G. M. Dzhafarly and A. I. Rubinshtein, Multiplicative systems of functions and harmonic analysis on zero-dimensional groups, Baku, Ehim, 1981 (in Russian).

[2] I. Blahota, G. Gát And U. Goginava, Maximal operators of Fejer means of double VilenkinFourier series, Colloq. Math. 107, 2 (2007), 287-296.

[3] I. Blahota, G. GÁt and U. GoginaVa, Maximal operators of Fejér means of Vilenkin-Fourier series, JIPAM. J. Inequal. Pure Appl. Math. 7 (2006), 1-7.

[4] N. J. FuJII, A maximal inequality for $H^{1}$ functions on the generalized Walsh-Paley group, Proc. Amer. Math. Soc. 77 (1979), 111-116.

[5] G. GÁt, Cesàro means of integrable functions with respect to unbounded Vilenkin systems, J. Approx. Theory 124, 1 (2003), 25-43.

[6] U. Goginava, Maximal operators of Fejér-Walsh means, Acta Sci. Math. (Szeged) 74, 3-4 (2008), $615-624$.

[7] U. GoginaVA, The maximal operator of the Fejér means of the character system of the p-series field in the Kaczmarz rearrangement, Publ. Math. Debrecen 71, 1-2 (2007), 43-55.

[8] U. GoginaVA, Maximal operators of Fejér means of double Walsh-Fourier series, Acta Math. Hungar. 115, 4 (2007), 333-340.

[9] U. GoginaVA AND K. NAGY, On the maximal operator of Walsh-Kaczmarz-Fejer means, Czechoslovak Math. J. 62, 3 (2011), 673-686.

[10] J. PÁL AND P. Simon, On a generalization of the comncept of derivate, Acta Math. Hung. 29 (1977), $155-164$.

[11] F. SCHIPP, Certain rearranngements of series in the Walsh series, Mat. Zametki 18 (1975), 193-201.

[12] P. Simon, Cesàro summability wish respect to two-parameter Walsh sistems, Monatsh. Math. 131 (2000), 321-334.

[13] P. Simon, Inverstigations wish respect to the Vilenkin sistem, Annales Univ. Sci. Budapest Eotv., Sect. Math. 28 (1985), 87-101.

[14] G. Tephnadze, Fejér means of Vilenkin-Fourier series, Studia Scientiarum Mathematicarum Hungarica, to appear.

[15] G. TePhnADZE, On the maximal operator of Vilenkin-Fejér means, Turk. J. Math, to appear.

[16] N. YA. Vilenkin, A class of complate ortonormal systems, Izv. Akad. Nauk. U.S.S.R., Ser. Mat. 11 (1947), 363-400.

[17] F. WeIsz, Martingale Hardy spaces and their applications in Fourier Analysis, Springer, BerlinHeideiberg-New York, 1994. 
[18] F. WeIsz, Cesàro summability of one and two-dimensional Fourier series, Anal. Math. 5 (1996), 353-367.

[19] F. WEISZ, Summability of multi-dimensional Fourier series and Hardy space, Kluwer Academic, Dordrecht, 2002.

[20] F. WEISZ, Weak type inequalities for the Walsh and bounded Ciesielski systems, Anal. Math. 30, 2 (2004), 147-160.

[21] A. Zygmund, Trigonometric Series, Vol. 1, Cambridge Univ. Press, 1959. 